\title{
PENETRACION DE LA HISTORICIDAD EN EL DERECHO CONSTITUCIONAL ESPAÑOL
}

\author{
Adrián Celaya Ibarra
}

Sumario: 1. La Constitución y la Historia. 2. Necesidad de la Historia. 2.1. Democracia y foralismo civil. 2.2. El foralismo y la democracia en el Derecho Civil. 2.3. El constante retorno del Derecho Foral. 2.4. La regla general y la excepción. 2.5. Democracia y foralismo en Derecho público. 3. La Constitución sustancial.

Con este título pronunció don Pablo Lucas Verdú una luminosa conferencia en San Sebastián que sigue teniendo actualidad porque, aunque se expuso en una fecha en que la Constitución era aún muy reciente, abría notables perspectivas para su interpretación y aplicación ${ }^{1}$.

\section{La Constitución y la Historia}

Ponía de relieve don Pablo Lucas las numerosas referencias de la Constitución a la Historia o a hechos que solamente se entienden como una realidad histórica que está más allá de la propia Constitución. Ya en su preámbulo declara la voluntad de «proteger a todos los españoles y pueblos de España en el ejercicio de los derechos humanos, sus culturas y tradiciones, lenguas e instituciones». Son palabras y conceptos que solamente se pueden entender acudiendo a la realidad histórica y social.

Pero además Lucas Verdú citaba una diversidad de textos en que la Constitución española hace referencia a hechos históricos y sociales:

1. El artículo 2 se refiere a «las nacionalidades y regiones» que integran España, conceptos que no se explican por la propia Constitución.

2. El artículo 2.2 habla de las «lenguas españolas» y en el párrafo 3 de las «distintas modalidades lingüísticas de España» como un patrimonio cultural.

1 Pablo LuCAs Verdú, «Penetración de la historicidad en el Derecho Constitucional español», conferecia pronunciada en el Primer Congreso de Derecho Vasco, San Sebastián 1982, pp. 21 a 71 en la edición de I.V.A.P. Oñati, 1983. 
3. En el art. 143, que inicia la regulación de las Comunidades Autónomas exige que las provincias que las constituyan, además de ser limítrofes, tengan «características históricas, culturales y económicas comunes» Y si se trata de provincias aisladas deben tener «entidad regional histórica».

4. La referencia a la Historia es básica cuando se trata de regular las competencias en materia de derecho foral, en el art. 149.1.8. ${ }^{\circ}$ en el que solamente se reconoce competencia «para la conservación, modificación y desarrollo» de «los derechos civiles forales o especiales, a las Comunidades Autónomas «allí donde existan».

5. La discutida disposición adicional primera respeta y ampara «los derechos históricos de los territorios forales».

No dejaron de observar y comentar estos textos que llaman a la Historia los primeros civilistas que al comentar la Constitución vieron que ésta rompía con una línea tradicional en España en la que las Constituciones, no acudían ni a la Historia ni a otros criterios externos a ella, como los valores que abiertamente proclama el artículo 1. ${ }^{\circ}$ de la Constitución actual, entre los cuales llama la atención el del pluralismo político.

No sorprende que los comentarios de los civilistas no fueran siempre favorables, y deseo subrayar la crítica de Clavero Arévalo, que Lucas Verdú compendia en estas tres afirmaciones:

1. Felizmente pasaron los tiempos en que el concepto de Constitución histórica imperaba entre las ideas antidemocráticas.

2. Nuestra Constitución, en la cuestión de las autonomías, se remite a tópicos históricos en momentos bastante delicados, introduciendo el tema en el terreno incierto de las ideologías (subrayado de Lucas Verdú) y de los nacionalismos de raíz histórica.

3. Impulsados por los artículos 143,1 y 147,2 a) de la Constitución que apuntan en esa dirección, la segunda hornada de proyectos de Estatuto siguen invocando una identidad histórica como razón o fundamento de su autonomía: se hable o no de nacionalidad ya se está introduciendo de todos modos en el sustrato resbaladizo de la historia. (Este último comentario carece de valor actual, una vez aprobados y con amplia vigencia todos los Estatutos).

\section{Necesidad de la Historia}

La crítica de Clavero a la presencia del hecho histórico en la Historia se basa en una concepción constitucional de tipo liberal garantista, que debe superarse. Exponía Lucas Verdú una serie de dicoto- 
mías que el liberalismo clásico consideraba, antítesis como las de colocar el Derecho escrito frente al consuetudinario; la democracia representativa frente a la democracia directa, o la Constitución escrita y codificada frente a la Constitución consuetudinaria e histórica. A estas dicotomías añade Lucas la del monismo formalista frente a pluralismo histórico social y el quietismo jurídico-político frente al dinamismo jurídico-social. Los ordenamientos constitucionales clásicos se resisten, seguía Lucas Verdú, a la estimación trascendente y a la relativización sociopolítica que implacablemente les afectará. De este modo tienden a petrificarse. "Los ordenamientos constitucionales demoliberales clásicos tienden a congelar la Historia, añadía en su conclusión tercera. Al pretender su permanencia y regular su producci'ón y cambio de acuerdo con sus propias prescripciones formales, propenden a soslayar la historicidad o realidades como los partidos políticos».

Quiero detenerme en comentar este extremo. Ninguna Constitución ni Código, ni otra disposición general puede desentenderse de la realidad histórica y social en la que vive. Es imposible aislarse de ella. Aunque lo pretendieran, las Constituciones de corte liberal no lo consiguieron, no se puede vivir de espalda a la realidad.

El entusiasmo que, especialmente en momentos de cambio sustancial, acompaña a los creadores de una Constitución les conduce a glorificarla y casi adorarla viendo con recelo cualquier interpretación libre y oponiéndose a su modificación. En España se ha producido también este fenómeno. Hay quien quiere mantener la Constitución a la letra (lo que es imposible) y considera poco menos que una traición cualquier intento de hacerla avanzar, aunque lo exija la realidad social. Este quietismo es la muerte de cualquier progreso o avance.

El jusnaturalismo del siglo XVIII pretendía hallar leyes eternas, basadas únicamente en la razón, para todos los hombres y todos los tiempos. La Revolución francesa y algunas posteriores pensaban hallar ese Derecho natural que descansa en la razón de todo hombre y que no exige ser jurista para encontrarlo y formularlo, un argumento con el que Napoleón se sentó a presidir la Comisión redactora del Código Civil. Redactado este Código, tan racionalmente, no podían admitirse cambios ni versiones diferentes y, según se dice, Napoleón se dolió en su destierro de que aparecieran los primeros comentarios, afirmando que su obra se había perdido.

En materia civil se hizo muy pronto patente el error de esa posición anti-histórica de la Constitución y el Código. Los revolucionarios querían acabar con toda interpretación y establecieron un recurso de casación directo al Parlamento, sin permitir otros alegatos que el texto de la 
ley. Parecían sobrar Jueces y Abogados, pero naturalmente la experiencia fracasó.

En el orden administrativo Francia fue dividida en departamentos desligados de la Historia y la realidad social, tomando en cuenta únicamente la superficie y población, algo que no ocurrió en la reforma de Javier de Burgos en España. Creo que todavía padece Francia esta desviación de la realidad y el espíritu jacobino enarbola la Constitución con la fuerza de la vieja expresión castellana, «defendella y no enmendalla».

En Alemania, donde la Codificación se retrasó hasta fines del siglo XIX, el dogmatismo jurídico trabajó sobre Constituciones y Códigos, como realidades puramente formales que la jurisprudencia de conceptos elaboró con gran maestría. Si la escuela de Savigny supuso, en la primera mitad del siglo XIX una reivindicación de la costumbre, pronto se impuso la dogmática conceptual y aprobado el Código Civil que es una gran obra legislativa, podía pensarse que se rozaba la perfección. Aquella obra admirable podía justificar el positivismo. Alemania tenía un gran Código y no había que buscar nada fuera de él. La ley es la ley y nada cabe fuera de ella. La única arma que debe usar el jurista, según este criterio es la ley positiva, analizada y pormenorizada por el método dogmático.

Parecía lógico suponer que si las leyes del sistema liberal se fundaban en la razón natural, era obligado proclamar su validez en todo caso. $\mathrm{Y}$ esto es lo que hizo el positivismo. Pero pronto hubo que reconocer que es muy difícil dictar normas universales basadas simplemente en la recta razón. Cada pueblo tiene criterios distintos sobre los mismos hechos, y por ejemplo, aunque todos estén de acuerdo, más o menos, en que hay que punir el asesinato, nunca estarán de acuerdo en la pena aplicable. Y nadie puede proclamar que la pena de muerte es más justa que la reclusión, y ésta más acertada cuando se limita a diez años que cuando se extiende a cuarenta. En el terreno civil, nadie puede demostrar que sea más injusto dejar a un padre que distribuya sus bienes entre los hijos como quiera que imponerle una legítima obligatoria. Aún hoy nos escandaliza pensar que el mismo Napoleón que como un hombre de razón se codeaba con los mejores juristas comenzara una sesión de la Comisión codificadora diciendo: «La naturaleza ha hecho de las mujeres nuestras siervas».

Además, aunque una Constitución o un Código fuera el más acertado para la generación que lo redactó, el paso del tiempo impone la necesidad del cambio. Las costumbres y los modos de vida exigen normas distintas. En la Edad Media se cortaba una mano a los ladrones, y hoy esta pena nos horroriza. ¿Quién puede prever la forma en que verán nuestros descendientes las penas de encierro en nuestras cárceles 
tan poco confortables y tan repletas que es incluso díficil cumplir las reglas de la Ley penitenciaria?

El positivismo paraliza la marcha del Derecho, que es algo dinámico, sobre todo en nuestros días, no se detiene nunca, y al pretender que la ley se imponga contra viento y marea termina llegando a resultados injustos.

«El concepto racional normativo de Constitución, decía Lucas Verdú (1.c. p. 29) formaliza el poder constituyente soberano que, teóricamente, reside en la nación, pero en realidad en el Parlamento, en la clase o grupos de la clase burguesa que lo controlan durante el siglo XIX y primeros decenios del actual (siglo Xx) o en el conjunto interclasista monopolizado por los partidos en nuestros días. El hecho histórico-político del poder constituyente con sus justificaciones revolucionarias iusnaturalistas frente al Antiguo Régimen se difumina y se olvida, para evitar que nuevas instancias revolucionarias amenacen al sistema recién establecido invocando argumentos análogos al iusnaturalismo revolucionario fundador del constitucionalismo».

Las ideas revolucionarias del siglo XVIII se convirtieron en el siglo XIX y Xx en la base sobre la que descansaron grandes abusos. Nunca el derecho de propiedad privada se había afirmado con tanta fuerza como en el sistema liberal que permitió enormes injusticias, ni la contratación había respaldado formas de explotación como las que surgieron en estos siglos, y aún padecemos en formas más soterradas, aun cuando se amparen en Constituciones democráticas.

El advenimiento del régimen nazi en Alemania, en plena euforia positivista, puso de relieve la debilidad del constitucionalismo formalista, que durante el III Reich impedía que surgieran instrumentos jurídicos o movimientos doctrinales que pudiesen frenar los abusos del dictador.

El positivismo reinante lo impedía. No puede sorprender que el positivismo se convirtiera, como dice Lucas Verdú, en una «reductio ad Hitlerum»

El positivismo, decía Radbruch, con su punto de vista de que «ante todo hay que cumplir las leyes» dejó inermes a los juristas alemanes frente a las leyes de contenido arbitrario e injusto ${ }^{2}$.

2 Gustav Radbruch, «Leyes que no son Derecho y Derecho por encima de las leyes», edición española por Ed. Aguilar, «Derecho injusto y Derecho nulo», Madrid 1971, p. 12.

Cuando hablo de Historia no me refiero a los comentarios e interpretaciones de los historiadores, sino a la innegable realidad de los hechos y condiciones de vida en que los hombres y los pueblos viven y se mueven. Por muy enemigo de la Historia que yo quiera ser nunca podré evitar que yo mismo, mis ideas, mis sentimientos, mis costumbres y mis mo- 


\subsection{Democracia y foralismo civil}

La verdadera democracia no pierde su sentido por aceptar los hechos históricos y la tradición. Nadie puede negar el carácter democrático de la Constitución inglesa aunque no exista un texto codificado.

Hay que reconocer que muchas vivencias históricas fueron no sólo antidemocráticas sino inhumanas, aunque también pueden encontrarse signos de autoritarismo en algunas Constituciones históricas que se titulan democráticas. Pero los derechos humanos que los ingleses afirman haber recibido en la Carta Magna o en el bill de derechos, aunque se hayan adecuado con enmiendas al mundo actual, nadie puede negar que son la raíz de la Constitución inglesa, como algunas de nuestras viejas costumbres, y especialmente las que obligaban al Rey o Señor, a jurar los Fueros y someterse a ellos, son la base de lo que llamamos democracia foral. La base del Estado de Derecho es la sumisión de todos, incluso los reyes o los gobernantes, a la ley.

Quizá la vivencia más inmediata del integrismo de algunos foralistas del siglo XIX nos fuerce a pensar que se trata de experiencias históricas caducadas, pero el análisis de las instituciones, tanto públicas como privadas, nos descubre cuáles fueron los pasos decididos que por la vía de la costumbre pusieron a pueblos antiguos en camino hacia formas menos autoritarias, como lo hizo el inglés al obligar a Juan sin Tierra a someterse a la Carta Magna, pero también algunos pueblos españoles, como el de Aragón con sus institucuiones, o Bizkaia cuando al redactar sus Fueros impuso al rey o Señor la obligación de jurarlos y someterse a ellos, creando la figura del pase foral como modo de control de la foralidad.

Sin perder de vista la conferencia de Lucas Verdú voy a plantear el problema de la perfecta compatibilidad de los derechos históricos con la democracia, separadamente, desde el punto de vista del Derecho civil, que fue el tema central de la conferencia o el del Derecho Público.

dos de vida, me hayan sido dadas por la sociedad en que vivo y en la que me he educado. Y por mucho que me condicione la actualidad, dependo aunque lo quiera negar, de muchas circunstancias que me han acontecido y me han formado.

Y es casi esencial a la vida, la diversidad. El artículo uno de la Constitucióbn al proclamar como valor esencial el pluralismo político está haciendo un llamamiento a la vida, a la realidad y a la historia, pues son ellas las que explican la diversidad de nacionalidades y regiones, de lenguas o de culturas. Ignorar esto, como han hecho en España todas las Constituciones históricas, es dejar la puerta abierta a la discordia, porque la realidad es más poderosa que todas las leyes. La Constitución de 1978, al reconocer estas realidades históricas, supone un avance notable respecto de todas las Constituciones anteriores. 


\subsection{El foralismo y la democracia en el Derecho Civil}

La reivindicación foralista en materia civil es muy antigua, anterior a la aparición de los nacionalismos, y quizá por ello no suscita tanta enemiga y oposición como en materia de Derecho Público. El movimiento a favor de las leyes y costumbres forales es una consecuencia del pluralismo que en materia de Derecho civil, estuvo siempre vivo en España. Los territorios de la Corona de Aragón (el mismo Aragón, Cataluña, el reino de Valencia y el de Mallorca e islas Baleares) mantuvieron hasta el siglo XVIII una autonomía, que era más bien soberanía del rey de Aragón, ejercida de un modo casi federal, que les permitió mantener sistemas jurídicos civiles propios, e incluso crear una literatura jurídica original. Esta situación se mantuvo, tras la reunión de los reinos de Aragón y Castilla en los Reyes Católicos, y, salvo en el caso de Valencia, ni siquiera se interrumpió por las tentativas centralizadoras y abolitorias de Felipe V, que en los Decretos de Nueva Planta, accedió a mantener la vigencia de las leyes civiles de los antiguos territorios. Es cierto que Felipe V, al mismo tiempo que presionado por la protesta social, reconocía los derechos forales (salvo los de Valencia) los hería de muerte al eliminar los órganos creadores de Derecho de estos sistemas jurídicos, sus Parlamentos y Cortes, prohibiendo además usar el catalán en los tribunales. A partir de entonces conservaron sus leyes civiles congeladas y sin posible desarrollo y así llegaron hasta los días de la transición democrática, porque el Código Civil de 1889, en sus artículos 12 y 13 mantuvo aún vivos los derechos civiles de los territorios forales.

Navarra fue también un Reino con su Derecho propio y en materia civil mantuvo esta condición aun después de la conquista por Fernando V, que no hay que olvidar que era un rey aragonés, hasta la Compilación de 1973. Los territorios vascos, en cambio, incorporados a Castilla durante la Edad Media, tuvieron más dificultades para crear y cultivar su Derecho civil, que únicamente quedó formulado por escrito en el Fuero de Vizcaya y en el Fuero de Ayala. El derecho de estos territorios se mantuvo en una convivencia no siempre fácil con el Derecho de Castilla.

Por todo ello, en la época en que se elaboraba el Código Civil había en España una serie de sistemas jurídicos que tenían vigor en pie de igualdad. ¿Qué decisión debían tomar los redactores del Código Civil?

Los sistemas jurídicos europeos, por lo común, al codificar su Derecho civil siguieron el modelo francés que hacía aplicable el Código en toda la República, eliminando las diferencias territoriales. En Francia fue esto posible por la fuerza de la Revolución, a la que las regiones no pudieron resistir, no sin que se sufriera en muchos lugares, como en 
Labourd, Soule o Benabarre, los territorios vascos del lado frances, la violencia de esta imposición, pues al fin y al cabo, pese a los alardes de universalismo el Código de Napoleón era muy francés y tuvo muy presentes las costumbres de París y en general el Droit coutumier, con olvido de los demás sistemas vigentes en el País y que se inspiraban en fundamentos muy distintos.

Cuando en el siglo XIX se planteó en España la necesidad de la codificación, los territorios de Fuero, y singularmente catalanes y aragoneses, habían preparado la defensa de sus sistemas jurídicos y resistieron la tentación centralizadora, muy presente en el primer proyecto de Código Civil de 1851.

Podía pensarse que la diversidad de Fueros podía ser superada con ventaja en un Código único de elaboración racional, que acabase con todas las peculiaridades de los derechos civiles forales. Esto podía hacer más sencillo el conocimiento de nuestro Derecho, aunque es ingenuo pensar que el Derecho que se expresa en la forma más sencilla sea el más perfecto.

Antes de la Codificación, pese a estar cegadas las fuentes de producción de los Derechos forales, se mantenían éstos vivos, pero encerrados en textos cada vez más antiguos, por lo que no puede sorprender que haya caído sobre ellos la tacha de ser un montón de arcaísmos, muchas veces anacrónicos. El proyecto de Código de 1951, que no llegó a entrar en vigor, se decidió a eliminarlos y seguir el modelo uniformador del Código francés.

Pero el Derecho Foral sobrevivió y resistió frente al proyecto de 1851. Le habían salido para entonces importantes valedores que formaban nuevos cuerpos de doctrina, defendidos por juristas notables, sobre todo en Cataluña, y, por supuesto la escuela histórica había alcanzado mucho prestigio. En esta situación, el legislador de 1888, prefirió mantener vivos los Derechos forales, aunque acordando que se redactaran unos Apéndices que recogieran el Derecho propio de cada uno de los territorios forales.

\subsection{El constante retorno del Derecho Foral}

La situación de los Derechos forales en la época de la Codificación era díficil. No solamente se habían eliminado los órganos legislativos en los Decretos de Nueva Planta, sino que, con la abundante producción legislativa en Castilla, que iba prodigándose en leyes generales, se ocupaban importantes parcelas del llamado Derecho foral, mientras los sistemas forales, que no se permitía mejorar, se presentaban cada día como más antiguos, y parecían cerrados a la modernidad. 
Hay que salir al paso de la acusación de arcaísmo, entre otras razones porque el Derecho civil evoluciona mucho más lentamente que el Derecho Público y las leyes antiguas pueden muchas veces mantener su vigencia en sociedades modernas. Al fin y al cabo, el Código Civil debe buena parte de su contenido al Derecho Romano, a las Partidas, a la reforma napoleónica e incluso al Derecho visigótico. Y pese a su pretensión racionalista el Código francés es hijo de su entorno histórico, del Derecho francés de los territorios de Droit coutumier, del Derecho Romano, en buena medida y también de alguna influencia germánica.

Se reconoce generalmente que el Derecho Civil evoluciona mucho más lentamente que el Derecho Público. Las Constituciones modernas dependen muy poco o nada de todo el Derecho anterior al siglo XVIII, mientras que en materia civil hay que buscar las raíces en distintas épocas de la historia y, por contraste, en el siglo XIX en Alemania, la resistencia a la codificación se apoyaba aún en el Derecho Romano.

El Derecho civil es también más resistente al cambio porque es muy díficil cambiar los hábitos y costumbres de un pueblo por ley, como la dura experiencia de la legislación civil soviética lo demuestra . Pese a que en el Derecho europeo haya gran similitud entre las instituciones, de origen romano, germánico, canónico, etc., lo cierto es que cada País y especialmente los que han vivido una historia independiente o autónoma, mantiene con tenacidad su apego a las costumbres civiles más arraigadas, que con frecuencia son mezcla de algunos de los elementos que he citado. Y así se explica que en España los territorios forales mantengan sistemas civiles propios, diferentes entre sí y diferentes del que existió en Castilla antes de la vigencia del Código Civil.

No hay que sorprenderse de que siempre que se quiere uniformar el Derecho civil existan fuertes resistencias y que pueda hablarse del retorno del Derecho foral, porque es un conjunto de normas vividas, díficil de erradicar cuando son fruto de costumbres centenarias.

Necesariamente nos debemos preguntar si realmente es buena la unificación, si el legislador debe romper esas que parecen excepciones al sistema (no son nada de eso, pues son sistemas distintos) y dictar un Código general para todos los españoles.

La única ventaja que puedo ver a la unificación es la que siempre se aduce, que simplifica y facilita el mejor conocimiento de un sistema único. Nadie puede demostrar, en cambio que el sistema catalán sea inferior al del Código civil o al del Código italiano o el alemán. Probablemente cada uno de ellos es mejor en el territorio que lo ha creado. El objetivo de una ley no es el de la sencillez y simplicidad, sino el de la justicia y seguridad. 
El mantenimiento de los Derechos forales es una riqueza para España, pues posee sistemas diversos, acomodados a las distintas partes de su geografía y, lo que es más importante, acomodados al talante y el carácter de los diferentes pueblos y culturas. La historia ha creado, por ejemplo, el sistema de legítimas y el de libertad de testar, y un castellano puede estar muy convencido de que la legítima es una exigencia de la Justicia porque se acomoda a los campos de Castilla, pero un navarro o un ayalés defenderán con muchas razones la libertad de testar porque es lo mejor para ellos y para su paisaje, que en palabras de un jurista vasco, es también una fuente del Derecho.

El legislador optó por la variedad, aunque en la época del Código Civil, desprovistos los territorios forales de un órgano legislativo, es claro que se les condenaba a una vida residual, cada vez con fórmulas menos actualizadas, más estancadas en el tiempo, y, en definitiva, se les llevaba a una previsible extinción, al menos a largo plazo. Podía decirse, y se dijo, que el objetivo era el de lograr un Código civil único para todas las Españas.

Para que los derechos forales tuvieran vida era necesario que reviviera alguno de los órganos de creación de su Derecho. Esto era difícil en el siglo XIX, en el que ni siquiera se reconocía la existencia de pueblos distintos en España (como lo hace la Constitución actual desde su preámbulo) ni, por supuesto, se confesaba la diversidad de idiomas. Se admitía la validez de algunas normas forales que ya parecían agonizantes, pero en modo alguno se podía admitir que esas normas se desarrollasen, que fuesen auténticamente vivas, para lo que era indispensable que los distintos pueblos de España pudieran crear Derecho nuevo. Por esta razón, la Constitución republicana de 1931, que no fue capaz de asimilar el hecho histórico como tal, se vio en dificultades para regular la vigencia y sobre todo la posible renovación del Derecho Foral y buscó en su artículo 15 la fórmula de que el Parlamento pudiera conceder a las regiones la competencia para legislar en materia civil, en abstracto, sin una referencia a la Historia ni a los Fueros y Constituciones propias de estos territorios.

De hecho, solamente Cataluña tuvo la oportunidad de ensayar una legislación propia y no encontró muchas facilidades.

Hay que reconocer que la fórmula de la Constitución de 1978 es mucho más acertada, pues concede a las Comunidades Autonomas, allá donde exista Derecho Foral, la competencia para su conservación, modificación y desarrollo. Es decir que la Constitución acepta el problema en los términos en que la Historia lo tenía planteado, y permite su actualización y puesta al día por quienes podían tener mayor interés en hacerlo, las correspondientes Comunidades Autónomas. La miseria de 
nuestro pensamiento jurídico consiste en que siempre existen personas interesadas en poner dificultades a este objetivo, y otras en exagerar sus dimensiones.

El art. 149,1,8. ${ }^{\mathrm{a}}$ de la Constitución de 1978 al acudir a la Historia, a los Fueros, usos y costumbres, admitía la existencia del problema, no lo eliminaba por simple derogación como en Francia; y lo resolvía de la forma más correcta, manteniendo el Derecho Foral, pero vivo, no disecado, como pretendió hacer el Código Civil. Comprendo la perplejidad de algunos juristas españoles, poseídos de la idea de superioridad del sistema central unificado ${ }^{3}$, que tienen muchas dificultades para precisar el ámbito al que alcanza esa competencia de las Comunidades Autónomas y constantemete le están buscando límites, pero lo cierto es que la Constitución no pone límites, simplemente se extiende la competencia legislativa de los territorios forales a la conservación, modificación y desarrollo del Derecho foral que en esos territorios aún pervive.

Al obrar de esta manera la Constitución es fiel a la trascendental declaración del art. 1, que propugna como un valor superior, además de la libertad, la justicia y la igualdad, «el pluralismo político». El derecho civil en España es también plural y la Constitución lo respeta. Decidirse por la unificación plena hubiera sido lo más simple, lo que otras Constituciones hicieron, pero también algo injusto y que rompía con el patrimonio heredado de la diversidad de sistemas, desconocía la diversidad cultural y los sentimientos de los distintos territorios en que regía el Derecho civil foral. «A mi juicio, decía Lucas Verdú en 1982, la penetración historicista que comporta el Derecho foral se tutela a través del valor pluralismo político (art. 1.1) que se manifiesta como autonómico (artículo 2 y título VIII) y que concretan el artículo $149,1,8 .^{\circ}$ y la Disposición Adicional primera».

Citaba también Lucas Verdú a Antonio Hernández Gil, que, desde su punto de vista civilista, sostenía que «el ordenamiento jurídico español ha roto con el planteamiento y la concepción formalistas. Las roturas han sido dos. Una arranca de la reforma en 1974 del Título Preliminar del Código Civil, al establecer como criterio interpretativo

${ }^{3}$ El hecho de que en las Universidades españolas se explique solamente el Derecho civil común encarnado en el Código Civil explica que los licenciados piensen que ese Derecho es el mejor, una especie de «ratio iuris» y tengan verdadera alergia a la aplicación de los Derechos forales. Estimo que la Universidad debería mostrar el Derecho comparado, que permitiría a los juristas españoles estar preparados para juzgar cualquier sistema, territorial o extranjero. Esta exigencia es más apremiante si se piensa en la diversidad de sistemas civiles de la Unión Europea. 
de las normas "la realidad social en el tiempo en que han de ser aplicadas"...».

«La otra gran ruptura es hacia arriba y precede a la Constitución. Mientras la realidad social es un factor de movilidad y de acercamiento a los hechos, los valores cumplen la finalidad de conseguir para el derecho el posible perfeccionamiento ético-social». Sin duda se está refiriendo a los valores que luego se proclamaron en en el art. 1 de la Constitución, entre los cuales aparece el del pluralismo político.

La Constitución se propone también romper con la acusación de anacronismo y antigualla que ha pesado sobre los Derechos forales. En lo sucesivo no quedarán petrificados, han de modificarse y desarrollarse y, por supuesto, utilizando las técnicas de nuestro tiempo.

La ponencia sobre esta materia que se presentó en el Congreso de Jurisconsultos de Zaragoza en 1981 afirmaba que «la competencia legislativa de las Comunidades Autónomas no se restringe, en modo alguno, a la situación actual de las Compilaciones vigentes: legislar supone innovar».

Y puntualizando mejor añadía la ponencia que «los Derechos civiles forales o especiales constituyen cada uno un sistema del que la correspondiente legislación e incluso la histórica, no es sino una expresión parcial, informada por principios seculares que le proporcionan posibilidades de autointegración. Hasta donde lleguen esos principios informadores llega la competencia de las Comunidades Autónomas» ${ }^{4}$.

El punto de vista fundamental es el de esos principios de que habla la ponencia, porque un Derecho foral no es una mera yuxtaposición de leyes, aunque estén reunidas en un texto legal. Lo importante son los principios que inspiran las leyes y las costumbres, principios que constituyen un sistema que es lo que da vida y, al mismo tiempo, originalidad, al Derecho Foral.

En los estudios recientes que hemos hecho los juristas vascos en relación con el Derecho civil vasco damos gran valor a sus principios inspiradores, entre los cuales destacan, el de libertad civil, que es común a otros sistemas forales, y la especial concepción del derecho de propiedad que es más comunitaria, no solamente en el aspecto familiar de la troncalidad sino también en la abundante formación de cofradías y hermandades, que responden a esa idea de actividad común que hace explicable el gran desarrollo que tiene entre nosotros el movimiento cooperativo.

${ }^{4}$ La ponencia, no publicada, de aquel Congreso fue elaborada por Jesús DeLgado ECHEVERRÍA, y lamentablemente no se publicó, por lo que no puedo citar su edición. 
La sentencia del Tribunal Constitucional de 12 de marzo de 1993 reconoció ampliamente las competencias de las Comunidades Autónomas en materia civil. Afirmó también que esta competencia permite integrar en el sistema autonómico no solamente la Compilación, sino las costumbres y otras normas propias de su ordenamiento.

Sin embargo, la misma sentencia entiende que esta competencia no es ilimitada sino que en todo caso ha de referirse «a instituciones conexas con las ya reguladas en la Compilación u otras normas de su ordenamiento». La palabra «conexión» que dio lugar a dos votos particulares abre una nueva polémica entre los intérpretes.

\subsection{La regla general y la excepción}

Buena parte de la doctrina española ha entendido que el art. 149,1,8 contiene una regla general: «Es competencia exclusiva del Estado "la legislación civil"»; y una excepción «sin perjuicio de la conservación, modificación y desarrollo por las Comunidades Autónomas de los derechos civiles, forales o especiales, allí donde existan».

Esta interpretación puede conducir a la aplicación del Derecho común, que es la regla general, para cubrir las lagunas, o a interpretar el Derecho foral en sentido restrictivo, como algo excepcional. La consecuencia es pésima para la vida de los sistemas forales que la Constitución trata de amparar, porque si interpretamos el Derecho foral por los principios inspiradores del Derecho común, que es un sistema distinto e incluso puede ser contradictorio, podemos llegar a distorsionarlo totalmente.

Don Pablo Lucas Verdú sostenía muy acertadamente a mi juico que «hablar de excepciones es un modo de expresión impropio. Se comprende que unos determinados casos escapen a una regla determinada, pero no porque sean excepciones de la misma, sino simplemente porque caen dentro de una regla distinta».

«La norma jurídica, como todas las normas, está condicionada, o sea, opera sólo si se verifican determinados presupuestos y se dan determinadas circunstancias. Está determinada por un orden lógico: el caso jurídico diverso, producido por diversas condiciones de hecho, hace surgir una configuración jurídica diversa, sujeta a una norma diferente. Está también determinada por un orden histórico: según tiempo y lugares, una ley positiva como una forma de gobierno, pueden ser útiles o perjudiciales. Los dos órdenes de determinación no quitan, sino demuestran, que se trata siempre de reglas y no de excepciones».

$\mathrm{Y}$ en su conclusión once declara. «El artículo 149,1,8 no debe interpretarse con arreglo al juego regla general-excepción. Por el contrario, contempla una regla general: legislación exclusiva del Estado sobre el 
territorio nacional de Derecho común y otra regla distinta, aplicable al ámbito, más restringido, de las Comunidades Autónomas con Derecho foral. No se trata, pues, de excepciones ni tampoco de privilegios de los territorios forales, sino de normativas diferentes. Los ordenamientos forales concretan el pluralismo autonómico en el campo de la legislación civil».

\subsection{Democracia y foralismo en Derecho público}

La conferencia de Pablo Lucas Verdú se pronunció en un Congreso en el que el tema central era la actualización del Derecho civil foral, o más bien las normas constitucionales sobre el Derecho Civil Foral, y el Derecho Público ocupa menos espacio por razones obvias. Además, creo que soy conocido como civilista, por lo que debo ser prudente cuando me adentro en materias de Derecho Público. Pero no sería justo terminar sin una referencia a la penetración del historicismo en la Constitución cuando regula instituciones públicas, teniendo en cuenta que en el trabajo que comento no pasan ignoradas.

Es evidente que toda la regulación de las Comunidades Autónomas en la Constitución de 1978 se funda en las Comunidades naturales que históricamente se formaron en España: una realidad anterior a la Constitución, que ésta no solamente no ignora sino que pretende encauzar por la vía democrática dando fin a las tensiones históricas que plantea. En lugar de esquivar el tema o recurrir a creaciones artificiales la Constitución toma en cuenta como base de la organización territorial de España, la realidad histórica.

En efecto, conforme a la redacción del artículo 143, solamente podrán acceder a la autonomía como Comunidades las siguientes entidades territoriales:

a) «Las provincias límitrofes con características históricas, culturales y económicas comunes». Se atiende a los lazos históricos, los culturales, que no dejan de ser realidades creadas a través del tiempo y los económicos que se refieren a una realidad social inseparable de un desarrollo histórico.

b) «Los territorios insulares», a los que no se pone ninguna otra acotación, pero no hay duda de que se refiere a Canarias y Baleares, dos conjuntos de islas fundidos en historias comunes.

c) «Las provincias con entidad regional histórica». Aquí también se recurre a la historia y se exige una identidad «regional» definida a través del tiempo, históricamente. A su amparo accedieron a la autonomía Murcia, Cantabria y La Rioja. 
d) El art. 144 de la Constitución parece romper la necesidad de los lazos históricos cuando autoriza a las Cortes generales para que, mediante Ley Orgánica, puedan autorizar la constitución de una Comunidad Autónoma cuando su ámbito territorial no supere el de una provincia y no reúna los requisitos del apartado 1 del artículo 143. Este precepto se aplicó únicamente a Madrid. No es discutible que Madrid tenga una clara identidad, aunque no sea precisamente «regional», pero es indudablemente histórica. Y cuando los pactos de la Moncloa decidieron que la autonomía se extienda a todas las tierras de España, no se podía excluir Madrid, que tiene una identidad innegable, y no solamente como capital del país.

El sistema autonómico regulado en la Constitución tiene, por lo tanto, un evidente respaldo histórico, pero no es éste el lugar de ocuparnos del tema con detenimiento. En cambio, conviene detenerse en el análisis de una norma que ya ocupaba la atención de Lucas Verdú en su conferencia de 1979. Es la disposición adicional primera de la Constitución, que ha dado lugar a muchos debates pero que debemos transcribir aquí. Dice así:

Disposición adicional primera. La Constitución ampara y respeta los derechos históricos de los territorios forales.

La actualización general de dicho régimen foral se llevará a cabo, en su caso, en el marco de la Constitución y de los Estatutos de Autonomía.

Estamos ante una disposición insólita en el campo del Derecho Constitucional, decía Lucas Verdú, una disposición que contradice la afirmación de la inconciliabilidad entre el Derecho Foral y el sistema constitucional, aunque la solución adoptada por nuestra Carta fundamental no satisfizo a los grupos nacionalistas vascos en las discusiones en torno a esta disposición. (p. 43)

Destacaba también que la Constitución no ha formalizado los derechos históricos porque ello supondría su desnaturalización. Si la Constitución se hubiera ocupado de describir los que llama derechos históricos, los hubiera convertido en derechos constitucionales y muy difícilmente hubiera acertado, pues no es fácil traer la historia a un texto político. Pero al ampararlos y respetarlos, sin definirlos, ha creado un campo de trabajo para juristas y políticos, que deberán definirlos, y regularlos. Se abre una gran zona de flexibilidad, pues la disposición puede ser entendida de muy diversos modos, y, a mi juicio, La labor de los políticos en un debate racional, es la que puede hacer que esta discutida disposición tenga un lugar central en el desarrollo de la Constitución. 
Los llamados, según esta disposición, derechos históricos de los territorios forales, que se crearon con el tiempo y a base de repetidas experiencias, que crearon costumbres arraigadas, caen en el seno de la disposición adicional, con una única condición, la de que no contradigan a la propia Constitución.

La disposición fue una iniciativa del P.N.V., que, no obstante no la votó por su disconformidad con el párrafo segundo que obliga a que la actualización de los derechos históricos se lleve a cabo «en el marco de la Constitución».

Lucas Verdú transcribía las palabras del senador nacionalista Federico de Zabala que se lamentaba de que «de ser unos derechos emanados y originarios del pueblo vasco y apoyados en él, pasen a ser una proclamación más bien retórica de un texto constitucional y, a partir de esta novación, tales derechos quedan viculados a la suerte de la Constitución y no a la voluntad del Pueblo Vasco».

Lucas Verdú pensaba que en lugar de decir la disposición que «ampara y respeta» los derecho forales, debiera haber dicho que «los reconoce y ampara» lo «que cuadra mejor con la naturaleza de dichos derechos». Es exacto, pero a más de veinte años de distancia hay que reconocer que la autonomía vasca, y la navarra, que muchos entendieron que eran los destinatarios únicos de la disposición adicional, se han visto muy favorecidas por su aplicación.

En primer lugar, esta disposición eliminó las dificultades que hasta entonces ponía la Administración para cualquier descentralización en materia financiera. Guipúzcoa y Bizkaia que perdieron su Concierto Económico por el Decreto derogatorio de junio de 1937, pudieron pensar que se abría una esperanza, cuando a la muerte de Franco se creó una Comisión para el estudio de un régimen especial para las dos provincias. Soy testigo de que por parte del Gobierno y de la Administración, que alegaban mil razones legales y de todo tipo, no hubo la más mínima posibilidad de una concesión a las aspiraciones vascas y mucho menos, de algo que se pareciera a una autonomía financiera. Y un buen número de miembros vascos de la Comisión, y yo mismo como asesor, presentamos la dimisión ante la negativa posición del Gobierno. Algo similar ocurrió, cuando años más tarde, el Consejo General Vasco quiso negociar la restauración del derogado Concierto. Cuando se negoció, en cambio, el Estatuto, teníamos el apoyo de la disposición adicional y, pese a que no faltaron las dificultades, el resultado fue muy positivo.

No sé si hemos tenido conciencia de que la autonomía financiera que nos concede el Estatuto, basada en la citada adicional, es la clave de nuestra autonomía y lo que la hace más original. El Gobierno Vasco tuvo la habilidad de negociar el Concierto Económico de modo que 
pierda totalmente cualquier aspecto de privilegio, de lo que se le había acusado, pero evidentemente nuestra autonomía, descansa en esta realidad financiera, que, además, vitaliza nuestras Diputaciones ante cualquier tentativa centralista del Gobierno central o del vasco.

Además de esto, el Estatuto utiliza también la Disposición adicional primera en el artículo 17 para autorizar la creación de la policía autónoma vasca «para la protección de las personas y los bienes y el mantenimiento del orden público dentro del territorio autónomo». Fuera del País Vasco solamente hay algo similar, aunque no idéntico, en Cataluña.

También se aplica la disposición adicional primera en el art. 16 del Estatuto, según el cual «es de la competencia de la Comunidad Autónoma del País Vasco la enseñanza en toda su extensión, niveles y grados, modalidades y especialidades, sin perjuicio del artículo 27 de la Constitución y Leyes Orgánicas que lo desarrollen, de las facultades que atribuye al Estado el art. 149,1,30. ${ }^{a}$, de la misma y de la alta inspección necesaria para su cumplimiento y garantía».

Las referencias a los textos constitucionales limitan ciertamente la autonomía y también es cierto que similares competencias en enseñanza se extendieron a todas las Comunidades sin invocar la disposición adicional 1. ${ }^{\mathrm{a}}$; pero el Estatuto Vasco fue el primero que se aprobó y dudo mucho de que si no hubiera sido tan amplio, abriendo el camino, las restantes Comunidades Autónoma hubieran alcanzado las mismas competencias. En el Estatuto de 1936, Euskadi podía crear centros de enseñanza, pero el Estado mantenía todos los suyos, podía crear otros nuevos y tenía competencias superiores sobre todos.

Hay muchos interrogantes alrededor de esta adicional primera y reconozco que el Tribunal Constitucional la ha interpretado en forma bastante restrictiva, pero no pierdo la esperanza de que esta doctrina pueda variar. Si la Constitución es muy flexible, ¿por qué la doctrina ha de ser inflexible?

\section{La Constitución sustancial}

No he de ocultar que estoy omitiendo una idea básica que D. Pablo Lucas expuso en su conferencia y en otros trabajos. Es la idea de la Constitución sustancial, que he dejado de lado casi adrede porque me costaría manejar este hermoso concepto con su maestría, dada mi escasa experiencia en temas políticos.

La Constitución sustancial se contrapone a la Constitución cerrada de los tradicionales modelos liberal-garantistas, que pretenden dejar el Derecho encerrado de una vez y para siempre en el cuadro de la Cons- 
titución y leyes que la desarrollan. El sistema liberal-garantista no admite que pueda invocarse el Derecho natural o la doctrina de los valores, ni que se atienda al Derecho consuetudinario, o se tengan en cuenta los cambios de la realidad social, ni los hechos históricos divergentes, como los derechos forales. El Derecho no puede desbordar el sistema cerrado que los grupos que crearon la Constitución o el Código tienen mucho interés en mantener sin merma, aunque aparezcan hechos nuevos o caduquen las viejas proposiciones. Las ideas nuevas no tienen modo de actuar, aunque un fenómeno nuevo, como lo fue el socialismo o los movimientos obreros, ponga en duda ese universo cerrado, El siglo XX ha sido testigo de muchas luchas sociales en que la burguesía constitucionalista no admitía ninguna transacción.

La idea de la Constitución sustancial trata de resolver esta contradicción. Porque la Constitución sustancial es una realidad que nos envuelve, no es un artificio, sino la vida misma en la que la Constitución ha nacido y que puede y debe hacerla evolucionar.

Según Lucas Verdú, la Constitución sustancial española se integra por dos elementos: el Monarca y el pluralismo político social, dos realidades anteriores a la Constitución de 1978. Pero esta Constitución en vez de desentenderse de la realidad sustancial, la respeta y la tutela. Es un conjunto de realidades que participan de la nota común modulada según sus propias características, del pluralismo. «El pluralismo no lo agotan los partidos políticos pues la Constitución vigente recoge un amplio abanico pluralista: político, pluripartidismo (art. 6) autonómico (art. 2, título VIII) social asociativo (art. 22) empresarial (art. 7 y 131,8) organizativo (art. 105 y 51.2) fundacional (art. 34) religioso (art. 16,3) lingüístico (art 3,20) simbólico (art. 4.2)» ${ }^{5}$.

Según lo expuesto, la penetración historicista en nuestra Constitución se verifica a través de esa Constitución sustancial.

«La historicidad del Derecho foral así como la sustancialidad constitucional, no son realidades antidemocráticas son simplemente realidades innegables».

Gracias a este llamamiento a la Constitución sustancial, la Constitución española de 1978 es una realidad viva, no un cuerpo petrificado.

${ }^{5}$ Este texto lo tomo literalmente, como algunos otros, de la conferencia que comento de D. Pablo Lucas Verdú, en la página 36 del texto publicado. 